\title{
Beyond documentation - The digital philology of interaction heritage
}

\section{Marc Leman \& Joren Six}

To cite this article: Marc Leman \& Joren Six (2018): Beyond documentation - The digital philology of interaction heritage, Journal of New Music Research, DOI: 10.1080/09298215.2018.1479428

To link to this article: https://doi.org/10.1080/09298215.2018.1479428

曲 Published online: 25 Jun 2018.

Submit your article to this journal ๘

Q View related articles $\widetilde{ }$

View Crossmark data $\nearrow$ 


\title{
Beyond documentation - The digital philology of interaction heritage
}

\author{
Marc Leman (10) and Joren Six (10) \\ IPEM, Department of Art, Music, and Theater Studies, Ghent University, Ghent, Belgium
}

ABSTRACT

A philologist's approach to heritage is traditionally based on the curation of documents, such as text, audio and video. However, with the advent of interactive multimedia, heritage becomes floating and volatile, and not easily captured in documents. We propose an approach to heritage that goes beyond documents. We consider the crucial role of institutes for interactive multimedia (as motor of a living culture of interaction) and propose that the digital philologist's task will be to promote the collective/shared responsibility of (interactive) documenting, engage engineering in developing interactive approaches to heritage, and keep interaction-heritage alive through the education of citizens.

\section{ARTICLE HISTORY}

Received 23 November 2017

Accepted 15 May 2018

KEYWORDS

Interaction; documentation; digital philology

\section{Introduction}

Traditionally, philology was defined as the love of learning' about cultural heritage and it implied a focus on critical editions and comparisons of important texts that define our history and cultural heritage (Turner, 2014). However, with the advent of the digital revolution, things started to change. Text became digitally available and the critical editing and ditto comparison was henceforth based on digital tools and digital methods, such as navigation or finding unexpected correlations via data mining (Jockers, 2013). A straightforward further step, then, was to broaden the notion of text and apply the love for learning' to all kinds of documents, including audio files and video files (Bressan \& Canazza, 2014). Accordingly, the traditional focus on critical editions and comparison of texts was extended to all sorts of actions on all sorts of multimedia documents, related to all sorts of cultural heritage, including the recent past (e.g. audio documents from the 1960s) and even the present (e.g. documentation of interactive art installations) (Bressan, Canazza, Vets, \& Leman, 2016). Today, the picture of a modern digital philology is that of a refreshed approach to the disclosure of cultural heritage, making documents usable with digital methods. In the light of these developments, digital philology can be defined as a science that aims at disclosing heritage-related documents in the most optimal way (with care, and using digital tools) such that veridicality, long-term preservation, easy access and so on, is ensured, and that users profit from its acquaintance.
Accordingly, collecting, digitising or storing documents would be considered an archivist's work rather than a digital philologist's.

However, the above characterisation of digital philology is still based on the notion of document. Yet, there are reasons to believe that the traditional role of documents in our culture may be changing. In this paper, therefore, we develop a slightly different perspective on digital philology, one in which we go beyond the notion of document and document-disclosure. One reason for going beyond the notion of document is that in our post-industrial culture, documents are currently no longer attached to a particular materiality (clay, stone, parchment, paper) nor to a particular modality (text, audio, video). Documents became multimedia information, often even a dynamic form of information that is fully embedded in interactive systems. Accordingly, the problems we are facing here are of a totally different order than the problems related to document materiality and document disclosure (Manovich, 2001). Moreover, when dealing with interactivity, we are dealing with information processing rather than with information as such. Accordingly, the information on which the interaction relies is floating (not attached to a carrier) and volatile (it appears and disappears). There is no longer the notion of a fixed amount of information, or even a document where information is in a rather stable way attached to a material carrier. Nevertheless, interactive multimedia systems tend to generate cultural value through

CONTACT Joren Six joren.six@ugent.be 을 IPEM, Department of Art, Music, and Theater Studies, Ghent University, Ghent, Belgium 
interaction, using information from an environment (e.g. the interaction environment itself) that is continuously changing. The value of the interactive multimedia culture tends to be based on interaction experiences with interactive multimedia devices, rather than with documents.

It goes without saying that the information-stream produced by an interactive multimedia culture poses enormous challenges for the digital philologist. If the information is indeed in constant flow and no longer attached to a dedicated material carrier, and if information processing is the key to support multi-modal interactions (by multimedia systems) rather than content or representations, then where is the notion of document? What happens with cultural heritage if heritage can no longer be defined in terms of a document-based concept? Clearly, a new vision on heritage, beyond documents is urgently needed.

In what follows, we argue that the digital philologists' former preoccupation with document disclosure needs an update. An approach based on the revitalisation of heritage-documents may no longer be sufficient and should at least be rethought, in the light of the nonmateriality of multimedia and the floating volatile nature of information processing in modern interactive contexts. We argue in favour of a more radical digital philology where heritage is seen as being embedded in a living culture of interaction.

To support our vision, we proceed in four parts. In the first part, we define what we mean by the living culture of interaction. In the second part, we consider the tension between heritage-documents and interaction, and we explore this tension by providing brief examples related to musical heritage. In the third part, we propose a general model of digital philology in which we aim at combining document-heritage with interaction-heritage. In the fourth part, we explore how a digital philology of interaction heritage can be implemented.

\section{The living culture of interaction}

Let us start with a more precise specification of what we mean by a living culture of interaction.

First of all, by interaction, we mean communication among agents, in a culture (Eliasoph \& Lichterman, 2003). Communication leads to interaction situations and, plausibly, interaction rituals (Goffman, 1967/2005); a series of codified actions and responses which are typically based on non-explicated expectations about the context. Such interactions typically involve intentions or goaldirected behaviours, which determine the communication in terms of future expected outcomes.

Without going into details, we can stipulate that culturally relevant social interaction is based on expressive communication, or exchange of expressions. Expression is thereby conceived as a bio-signal that is rooted in affect and motor reflexes and that is culturally shaped on the basis of codified habits that are developed through learning and habituation, including the use of tools and machines (Leman, 2016).

In line with previous thinkers (such as, Darwin, 1890; Goffman, 1967/2005; Hume, 1777), expressive acts can be seen as basic ingredients for social communication that ultimately culminate in cultural expressions as we find them in the arts. Seen from that angle, expressive acts in agents evoke expressive responses in other agents that inhabitate the cultural environment. The mutual exchange of expressions among agents brings about selfreinforcing dynamics that are likely to establish a culture of expression, often with strongly ritualised characteristics. The outcome can be understood as a higher-level state of expression, called a homeostasis, or 'equal' or 'maintained' state of expression (Leman, 2016). Culture can thus be seen as an emerging outcome of mutual expressive communication among agents of particular cultural context or environment. Each outcome thereby represents a homeostasis of expression, either material (in stone, on paper... ) or immaterial (as experience, as interaction).

And although interactive multimedia systems, as we know them today, do not (yet?) possess the kind of intentional, expressive and reward-driven sophistication that characterises human interaction capabilities, some of these systems can already provide sophisticated dispositions for the human expressive response or display particular expressive and goal-directed behaviours themselves. Such systems have floating information processing capabilities that put them in the center of a culture of interaction. They become core components of the dynamics that lead to expressive homeostases. However, while these systems play an important role in our living cultural heritage, these systems go far beyond the notion of document. In fact, they add a new layer of machine-based cultural interactivity.

Secondly, what do we mean by a living culture of interaction? A living culture may be distinguished from a dead or frozen culture. When a culture is said to be living, then it is likely that there is an inherent drive to create new expressions that have the potential to change that what is commonly accepted as expressive homeostasis (Elias, Dunning, Goudsblom, \& Mennell, 2000). This drive for innovation, we assume, is based on the motivation and reward system of each cultural agent (Salimpoor, Zald, Zatorre, Dagher, \& McIntosh, 2015). And while inherent motivations and reward mechanisms are not yet implemented in machines, it is known that machines are built such that they exploit the human motivation and reward 
system. The interactive multimedia systems for gaming are well-known examples of machines that exploit human motivation and reward mechanisms (Lorenz, Gleich, Gallinat, \& Kühn, 2015). The outcome is that interactive multimedia systems thus contribute to the creation of new interaction situations, and hence, to a living culture of interaction and expression.

It is known that tools play an important role in the formation of a culture (Tomasello, 2010). Interactive multimedia systems can be considered as a very particular type of tools because they are intrinsically interactive and can be based on autonomous goals, expressive qualities and floating volatile information processing. Unlike the tools from the past, but similar to human agents, interactive multimedia systems have the capacity to mediate and co-create the expressiveness of the culture of interaction. And whether they generate text, audio, video, or whatever document, or information, their essence as cultural heritage is not in how they establish the materiality for information, but rather, in how they realise interaction processing. It is less how they deal with documents, or information, if any, but in how they respond, and add to expressive back and forth responses of other agents. In fact, in as far as interactive multimedia systems contribute to cultural development (think about machines that compose lounge music in hotels and other public places Briot, Hadjeres, \& Pachet, 2017), they become agents that inhabit a cultural environment to which they contribute. Next to the human agents, interactive multimedia systems gradually become partners in a living culture of interaction.

We see interactive multimedia systems therefore as agents within the culture of interaction. This culture has an advanced digital technology, based on fast communication networks, body area networks and smart environmental monitoring, augmented and virtual reality simulation, artificial intelligence and so on. All these technologies are based on information processing. And despite the fact that the material carries of information can be turned into heritage-documents (for instance, the Nokia cell phone as testimony of mobile culture in the late 1990), our post-industrial culture is definitely far more interested in artefact innovation (i.e. new cell phones) than in turning artefacts into heritagedocuments (i.e. collecting cell phones and preserving them). The question is how digital philology deals with this living culture of interaction, given its mission to promote and shape cultural heritage.

To further clarify our concept of living culture of interaction, let us imagine that our culture would destroy any obsolete interactive multimedia tools, in order to prevent them from becoming a document of the interactive multimedia heritage culture.
Question: Assume that such a culture exists, would it be without heritage? Answer: Obviously, we would define heritage in relation to peoples' memories and the existing interactive skills, which they learn from generation to generation, such as in oral cultures. So, the heritage of that culture would be carried, and propelled, by interactions among the agents. Heritage would be defined in terms of qualities of interaction processing, by the interaction rituals and all sorts of temporary tools that support these rituals. The tools themselves would not be considered as particularly valuable because they are temporary. The focus would be on skills, and on ways of transferring skills to the next generations.

Now assume the presence of a digital philologist of interactive multimedia systems in that culture. What would her preoccupations be as a scholar? Obviously, all her attention would be devoted to caring about heritage. To do so, she would invite human carriers of tradition and ask them to explain their experiences with temporary interactive multimedia systems. She would organise workshops in which such tools are revitalised before they disappear. In short, she would be concerned about keeping the tradition lively, innovative and selfreinforcing, because that tradition is essential for that culture.

Now, the reason why we introduced this little thought experiment is that it suggests the viable existence of a heritage with a focus on interaction processing, using interactive multimedia systems, but without the intention to turn them, or preserve them, as interactive multimedia documents. But as a matter of fact, that imaginary world may actually resemble our current post-industrial culture. Our culture gives rise to ambivalent feelings about heritage-documents. On the one hand, documents are considered important for a further development and understanding our culture. On the other hand, documents can not capture the essence of our living culture because the information processing inside the interactive multimedia systems, the essence of interaction, cannot be captured by documents.

In any case, we feel that in a living culture of interaction, heritage-documents can be more than just deepfreezed documents. We have little value in heritagedocuments that cannot be accessed, that cannot be interacted with, and therefore, we believe in digital philology as a discipline that should at least revitalise heritage-documents, to make them useful again in our living culture. However, while philology, for many centuries (Turner, 2014), aimed at revitalising heritagedocuments, we are now confronted with the task of how we can learn from a living culture of interaction where heritage is less attached to document carriers, similar to oral cultures. 


\section{Document-heritage and interaction-heritage}

Obviously, one possible solution to these ambivalent feelings about documents is that heritage should get constantly revitalised and that through the digital philologist's revitalising activity, heritage is kept vital and innovative. But can this be realised in practice? Let us consider a few cases that illustrate aspects of this ambivalence between document-heritage and interaction-heritage.

\subsection{The synthi 100}

The first example is a synthesiser. Over the years, its status evolved from instrument of the artistic avant-garde elite to a deep-frozen document, to an instrument of an interaction culture based on dance-music and fed by social media.

The synthesiser is the vintage EMS-Synthi 100 analogue synthesiser, owned by Ghent University's institute for psychoacoustics and electronic music (IPEM). Only 30 of those complex synthesisers were made, by hand. And as they contain slightly different electronic components, each Synthi 100 is to be seen as a unique piece of craftsmanship. Today, only a few Synthi 100s have been preserved in working state. UGent's Synthi 100 was acquired in the mid 1970s to form part of the institutes production studio for radiophonic applications (in a joint venture with the Belgian Radio and Television Broadcasting Company, BRT). The Synthi 100 was used for about 15 years, up to the early 1990s when digital equipment was introduced in the studio. From that moment on, the Synthi 100 was considered obsolete and it quickly turned into a document of the past, the so-called musical avant-garde. For about 25 years, the Synthi 100 stood in a corner of the lab, silently (except for some sporadic wake ups for didactic purposes), and neglected, not as heritage-document, but as living instrument. Fortunately, the synthesiser was not destroyed, as it would have been in a no-document-heritage culture.

Then in 2013, thanks to renewed interest in analogue equipment, things started to change. The Synthi 100 was showcased and demonstrated during the celebration of 50th anniversary of IPEM at the University's Aula. Surprisingly, some 30, mostly young, people attended the workshop. Thanks to that public interest, the Synthi 100's electronic circuitry got restored, and since then, the Synthi 100 became very popular again. It revitalised.

The stages of the synth are illustrated in 1. The Synthi 100 has meanwhile been used in different public performances such as the $\mathrm{AB}$ concert venue in Brussels, the Krook in Ghent, the Entrepot in Bruges. At those public performances, the machine attracted much attention. Apparently, the good old Synthi 100 got a new place in the culture of interaction. Currently, the device is fully connected with digital equipment. The Synthi 100 's popularity is quite impressive, probably because the sounds that come out of it fit the modern dance and pop culture aesthetics. Many artists admire the particular sound, and it's scent of former times, say, heritage. Is this merely nostalgia? Or is there something more? In any case, the transition from document-heritage to interaction-heritage illustrates a remarkable shift in heritage status. In fact, the Synthi 100's status as an instrument of the past, as a witness of the musical avantgarde, got overrulled by its potential for expressive communication. In all public activities, people focus on its expressive communication power. The Synthi's particular sound texture is probably the real reason why the synthesiser has such a status among experts. Its potential to renew expressive communication is still valid and this expressive potential should therefore be understood as a key element of the Synthi 100 when seen as heritage. It's historical role in the musical avant-garde has to be explained and illustrated but its particular sound can be easily compared with modern computer sounds. Its history is more a kind of a mystery to young people, but its sound turns it an attractive piece of working heritage. (a)

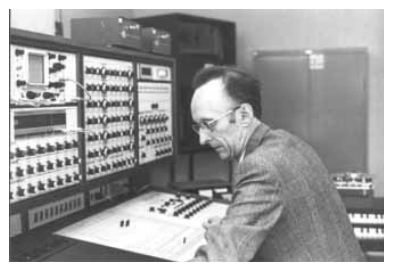

(b)

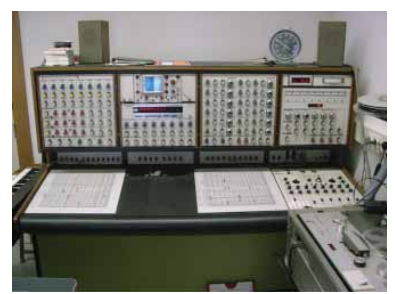

Figure 1. Three stages of IPEM's EMS Synthi 100. (a) The first stage is situated in the 1960s-1980s, when the synthesiser was used to contribute to electronic avant-garde music (featuring ir. W. Landrieux). (b) The second stage is situated in the 1990s, early 2000s, when the synthesiser turned into document-heritage. (c) The third stage is situated right now (2013-2017). The synthesiser has been restored and re-contextualised as part of an interactive music game, called SoundBikes (Maes et al., 2018), created for the opening event of the Krook, Ghent, March 2017. The music is electronic dance music, created by the Dewaele Brothers (2ManyDJs). 
Overall, the efforts in revitalisation of the Synthi 100 required particular supportive actions such as restoration, workshops to learn people how to use the device, making the device fully compatible with up-to-date digital technology, using it during (live) performances, making it participate in exhibitions and so on. As many people from different institutions came up with new ideas and initiatives for interaction-heritage, the Synthi 100's revitalisation was the result of a bottom-up collaborative effort that seemed to be driven by the urge to express.

Could this revival have been the work of a certified digital philologist with a well-developed top-down strategy about heritage revitalisation? It is unlikely that a single person could have done it. However, such a person could have contributed to the revitalisation, by coordinating actions, by playing the role of heritage catalyst, so that the instrument became part of a living culture of interaction.

\subsection{The BilliArt installation}

The second example is an interactive multimedia installation. This is just one example of the many interactive multimedia systems that raises questions regarding documentation and how documentation of interactive multimedia should be handled in view of heritage.

This problem of documentation goes way back to the 1960s, and the advent of the post-industrial music culture, with parallel developments within classical music, avant-garde music, jazz and pop music. While the practice of jazz and pop was mainly interaction-driven (e.g. using improvisation, multimedia and embodiment as key ingredients), classical and avant-garde music were mainly document-driven (e.g. using scores), and both cultures were keen on documenting star performers (e.g. photographs, films, texts).

Many composers of the avant-garde scene, for example, were documentalists of their own creative work. They wrote and published scores as documentation of their own creative activity. They produced music by the strict organisation of audio-structures (e.g. by cutting and pasting tape-fragments according to pre-composed time lines) and they did that very often in centres that documented their output in archives such as radio and TV broadcasting centres and universities. But towards the end of the 1960s, this approach to self-created heritage started to change. For example, proponents of the Fluxus movement challenged this document-driven approach to art production radically (Mertens, 1983). Also, mixed media, aleatorics and interactive systems started to exert influence, especially on composers who worked with multimedia, interaction and improvisation. The major reason for this change may have been the attitude towards technology, in particular, the idea that technology changes, becomes better and easier to use. Documenting a technological setup appears obsolete when every now and then there is a better solution to your technical problem. Moreover, interactive devices are often built for particular events. When the particular event is finished, then the interactive devices have to be dismantled. Often, the installations are too big to be kept alive. Nobody wants to store them, and again, the technology rapidly becomes old-fashioned and obsolete. So why documenting all of this, then?

New tools may become available and allow an easy remake of the former installation. At best the modern composers can use bits and pieces of their work in other work. Meanwhile, our culture has fully embraced the interactive multimedia systems and, consequently, the question is: what should we document, and what can we document? We have devices and programs, but these are technical solutions to interactive environments. When the technologies become obsolete, they don't provide an access anymore to the multimedia culture that they once supported.

An example is the BilliArt installation (see Figure 2). As described in Vets et al. (2017), the BilliArt installation consists of a collaborative environment based on the carambole billiards game that offers users the possibility to participate in a jazz-inspired music improvisation, augmented with visual feedback. The installation is designed to promote interaction among the users. The billiard game thereby offers dispositions for interacting. Its reward-based approach aims at stimulating the motivation to engage in the game. This reward system is realised by balancing predictable and unpredictable output, and by reinforcing the feeling of reward, irrespective of the level of musical training.

The BilliArt installation combines real-time motion tracking of billiard balls with visual and auditory feedback. The advanced techniques of motion tracking and real-time visual feedback need to be carefully calibrated because the components need to work together in order to be able to create a successful experience. Due to the fact that the BilliArt installation consists of many components, there are also many points of potential failure which does not bode well for longevity. In their paper, Vets et al. (2017) hint at improvements and several versions of the installation, which immediately raises questions with regard to which version or critical edition to potentially re-enact.

The BilliArt installation poses fundamental questions to the documentalist nature of a digital philologist, not in the least about how and what to document from interactive multimedia systems, especially in view of a remake of the installation. It is likely that a remake can 
(a)

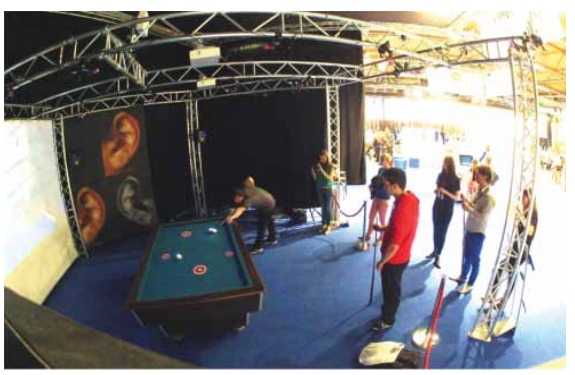

(b)

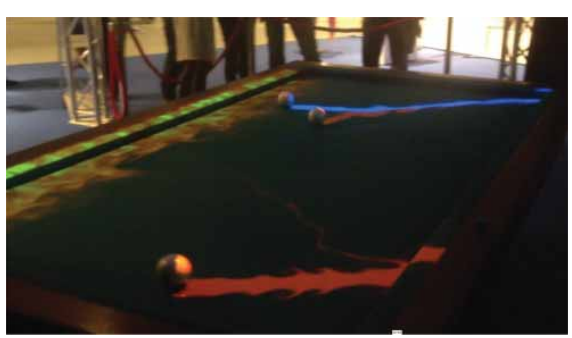

Figure 2. The BilliArt installation. Users play a technology-enhanced version of the billiards game. While playing, they generate machinebased, jazz-inspired music improvisation, augmented with visual feedback. (a) An overview of the installation. (b) One of the visualisation modes of the visual feedback.

be done with different interactive technologies. Hence, the essence for the digital philologist is the understanding of the interaction dynamics of the system, how the body movement of the participants is captured and how the table should respond in terms of visuals and sounds. Given this context, the role of the artist is often underestimated. An artist may know that the technologies of an installation rapidly become obsolete. Consequently, the intended upgrade, or intended refusal to upgrade, may be an artistic choice to be respected. What it all shows is that interactive multimedia systems raise questions regarding documentation and how documentation of interactive multimedia should be handled, even in view of keeping things working, or in view of a re-enactment in 10 years from here.

\subsection{Armand Hutereau's documentation}

The third example focuses on documenting, or the art of creating documents. Given the fact that documenting is itself based on a culturally dependent action, documents are not value-free but based on viewpoints that people have, without them being aware of the fact that they have those viewpoints. In that sense, the act, or art, of making documents, is itself part of a living culture of interaction.

Documentalism can be illustrated with the example of an expedition, in 1911, by Armand Hutereau, to the northern zones of the Congo. The expedition resulted in many drawings, two early silent films (Seiderer \& Schellow, 2017) and photographs with a particular focus on the 'hidden regions of the female body'. The results of the expedition were published posthumously by Hutereau (1927). The expedition also contributed to the oldest documentaries of music in Middle Africa. Hutereau made sound recordings on Edison wax cylinders (carried in boxes in the jungle, see Figure 3). However, the sound documents reveal the technological limitations at the time and, above all, the cultural perspective of the person who took the snapshots.

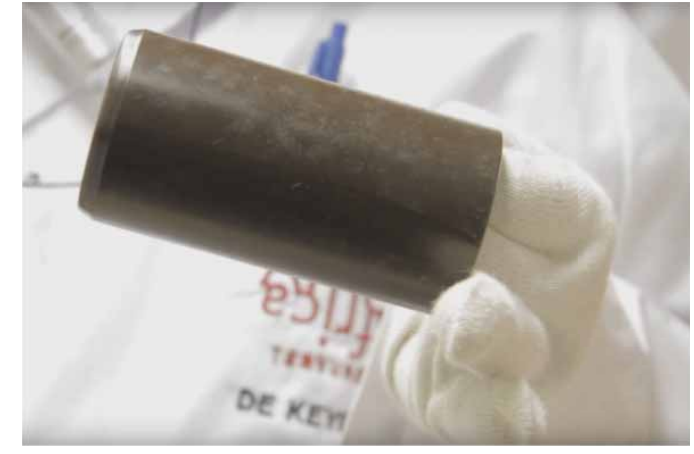

Figure 3. One of the wax cylinders recorded in 1911 in Northern Congo by Armand Hutereau. The cylinders are preserved at the royal museum for Central Africa in Tervuren, Belgium.

While Africa's cultural heritage is based on interaction, its music forms part of a multi-sensory experience, based on dance-music- embodied narratives. However, driven by the technology of 1910, the documentalist collapsed this living culture to the audio documents on wax, as if that culture produced music separated from the interactive multi-sensory interaction experience. In fact, the chance that a living culture could ever be re-established on the basis of these audio-documents alone is very small. The documented culture is a frozen heritage, void of its vitalism. Therefore, the documents will continue to offer a very particular point of view on a former rich living culture, interaction-based.

In that sense, there are many parallels with our postindustrial culture of interaction. Documents will hardly do justice to the real culture from which they have originated and will move digital philologists into providing critical editions, extending the circumstances and resources that were merely 'snapshotted'.

Fascinated by the culture of interaction, a digital philologist may take a few snapshots of ongoing interactions, to be stored on an interactive website document. However, like Hutereau's achievement, the snapshots will not be value-free and depend on the observer's viewpoint. 
And it could be a group of observers all snapshotting the interaction. However, the rule that applies to all documentarists is that snapshotting collapses the interaction into a document, thereby revealing the proper states of the observer and its snapshot-technology without having the capacity to capture the real interactivity. Seen from that perspective, documentation reveals basically how the observer, limited by the technology, looks at interaction.

All the above examples challenge the notion of document. The Synthi 100 music synthesiser was an example of an interactive device that first turned into a document of the avantgarde heritage, and then became revitalised to become part of a new culture of interaction, based on dance music and social networks. Currently, the Synthi 100 is considered heritage, but it's value is due to its new role in the living culture of interaction. The BilliArt installation illustrates an other challenge, namely that of the role of documenting interactive multimedia systems in view of their further use in the living culture of interaction. As technologies become obsolete, these installations easily turn into documents, whereas one may want to keep them alive. Finally, the example of Armand Hutereau's documentation illustrates that the act of documenting is not value-free, especially in view of the idea that documenting could capture essential features of a culture of interaction. Rather, documenting seems to create a particular heritage viewpoint.

\section{Documentation and interaction}

On the basis of the above examples, it is possible to draw a rough picture of digital philology. The picture is based on a dual interest in how to handle heritage, both as document and as interaction.

\subsection{Beyond materiality}

Heritage with a focus on documents has a typical interest in the preservation of the materiality that is associated with the document. Even in the case of interactive multimodal systems, it is often possible to point to the material components of the systems: computational devices, sensors, projectors and so on. And while the content produced by interactive multimodal systems is only existing in a working electronic circuit, there is still the electronic circuit that can be seen as a document, as material testimony for the system's interactivity heritage.

The documentation centre of the Logos foundation especially contains such material testimonies. The Logos foundation is home to the Robot Orchestra: the largest fully automated acoustic orchestra in the world ${ }^{1}$. Next

\footnotetext{
${ }^{1}$ See http://logosfoundation.org
}

to performing scores, they are also able to interact with performers using gesture recognition technology. Next to their own productions, logos has been inviting artists to present their work which could take many forms: sound installations, acousmatic compositions, contemporary classical works, interactive compositions and so forth. During the last 50 years, the Logos foundation has been diligently documenting many aspects of their activities. This includes audio recordings, annotated scores, textual descriptions, photos and videos of activities. Also made available are mechanical drawings, electronic schemas of robots together with the source code of software driving them. Some of the audio recordings are compiled on thematic albums and released in public domain on the Logos foundation website. Combined this material document material aspects (mechanical, electronics, software) and audio-visual documentation of interactions with Logo's robots. The robots themselves, however, are tools for expressive communication.

Similarly, the previously mentioned Synthi 100 is a nice example of a music instrument (not yet a full interactive multimodal system, though) whose precious electronics is considered to be a value in its own right, even if the electronics is no longer operational and the music instrument is no longer functional. In other words, the Synthi 100 as the material object has a status as document-heritage because its materiality is a testimony of the cultural environment and engineering craftsmanship of the 1970s. Other documents such as audio recordings, video recordings of avant-garde composers working with the Synthi 100, will enrich this document-heritage, providing the key elements to learn about the music life of the avant-garde.

In contrast, heritage treated as interaction has a main focus on the functionality of the device, on its role in activities that go beyond the materiality of the electronics, such as the generation of particular sound timbres, in short, its potential to innovative expressive communication. Similar arguments can be formulated in favour of using, say, a Stradivarius violin for playing a contemporary violin piece. The instrument would be a documentheritage showcase in the context of a music instrument museum. However, by using the instrument, rather than exhibiting it, it becomes a tool for innovative expressive communication.

\subsection{The cultural value chain}

An important issue in philology, is to consider heritage in view of a cultural value chain. But while documentheritage attributes value to materiality and testimony, interaction-heritage attributes value to expressive communication and the ability to function in a living culture 
of interaction. Obviously, the Stradivarius' or the Synthi 100 's value as document-heritage interferes with its value as interaction-heritage, and musicians are often well aware of both values when playing heritage instruments.

However, when dealing with interactive multimedia systems, the estimation of value may be challenging because the longevity of a systems' expressive potential may be short. Given the constant drive for innovation, many interactive multimedia systems become quickly obsolete and unsatisfactory in view of new devices whose new expressive potential encompasses the old expressive potential. For example, devices may be too slow or not powerful enough in view of massive real-time data processing. The problem is related to the difficulty of building satisfactory materialities, that is, satisfactory hardware whose materiality is essential for obtaining the expressive potential.

In contrast, it is likely that processing platforms (such as Max/MSP, Ableton Live, Audacity, Processing), plugins and future artificial intelligence algorithms of the interactive multimedia culture have a greater longevity as interaction-heritage because their potential to contribute to innovative expressive communication is not restricted to particular fixed or pre-defined devices. These software tools are building blocks or ingredients to new build interactive multimedia systems. Given the fact that they exist as algorithms, their relationship with materiality is rather independent of concrete hardware solutions. As software, these tools can migrate to different hardware platforms, and, as software, they tend to lack the materiality that can be captured as documentheritage.

Overall, there is a tension between document, interaction and heritage. Document-heritage is linked with materiality, whereas interaction-heritage is linked with expressive communication potential. Many people seem to like a mix of materiality and expressive communication potential and they consider it an added value to the development of new expressive forms. Sometimes, the materiality of obsolete technologies turns out to be a key ingredient of interactive communication (e.g. the revival of the LP and turntable).

\subsection{Interaction as oral heritage}

A focus on documentation, databases and data mining may be characteristic for a particular viewpoint on digital philology that focuses mainly on veridicality and critical documentation, including history and cultural analysis. But interaction is obviously very different from the focus on documents, although one could always argue that the act of documenting is also a form of interaction, and therefore, that the art of documenting forms part of the living multimedia culture of interacting.

However, the act of documenting may not be the essence of the living interactive multimedia culture as we know it today. That essence, as argued, deals with innovative expressive communication, where interaction drives the expression of a living culture. Interactive multimedia systems play a key role in innovative expressive communication. The intrinsic cultural value of interaction is probably un-documentable, despite the fact that documentary snapshots can be taken. In that sense, the intrinsic cultural value has much the same status as the heritage of an oral culture in Africa. Its heritage is passed down from previous generations to the current generation, through interactions among members of the culture. While these interactions lead to habits and interaction rituals, its value is distributed among the population who carries the culture collectivity. This collective culture, through habits and rituals, then defines the living cultural heritage. That heritage is a living phenomenon driven by expressive communication, which is based on mutual exchange of bio-signals and codified gestures, regardless of whether it is documented. The fact that individuals are raised in a cultural environment implies that individuals will (partly) learn that culture and frame their actions in that culture. In the context of interactive multimedia systems, individuals learn how to handle processing platforms, how to use those algorithms as parts of new algorithms, in short, they learn and know how to handle the building blocks for building interactive devices. Through their expressions, these individuals will try to mark their position within that culture and due to the mutual exchange of expressions, there will be an evolution of the global expressive nature of the culture, which in turn will be perceived and understood as heritage. What is to be learned as an individual in this culture is obviously expressive communication: how to exchange expressions with other people, how to respond to their expressions, how to deal with tools that realise these expressions, how to make installations to expressively interact with, how to use these expressive communications in the context of the known expressive interaction rituals. Seen from that perspective, multimedia cultural heritage is an emergent outcome of human interactions and their associated rituals.

\section{Implementation of future digital philology}

As suggested in Figure 4, the development of activities that curate heritage may involve two complementary cycles. One cycle has a focus on documentation, for example, through digitisation and meta-data description, comparison (e.g. through reliability tests, Six, Bressan, \& 


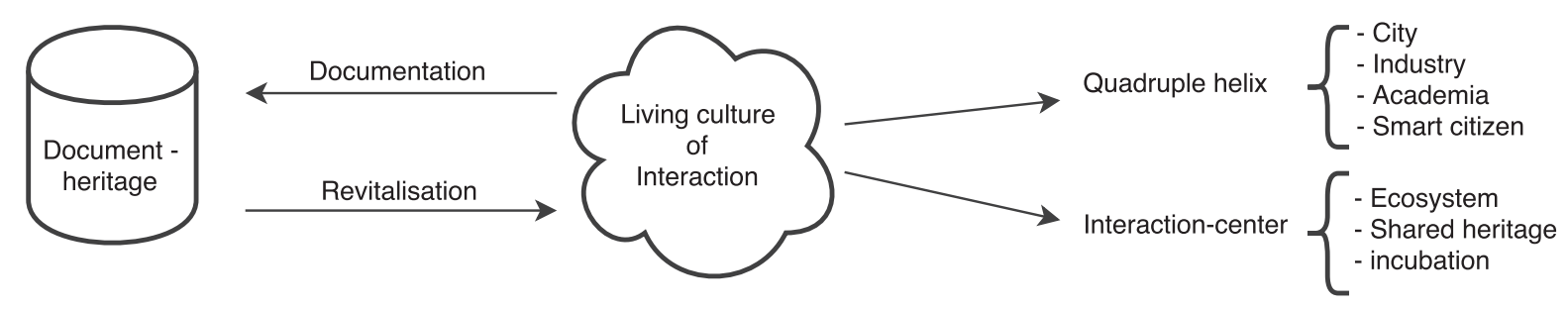

Figure 4. Coexistence model of documents and interactions.

Leman, 2018), studies of how to document interactive multimedia using social media and multi-perspectivistic database approaches, and related approaches. Another cycle has a focus on the heritage values generated by the culture of interaction, for example, through the restoration of equipment (the Synthi 100 example), through tools that open up documents as sources of inspiration for new forms of interactive expression, through the exploitation of heritage in view of new expressive forms. We believe that these two cycles should be kept integrated because of their contribution to the living culture of interaction. However, ways to keep these cycles integrated may require new types of curator activities from the part of a digital philologist. We focus here on a non-exhaustive list of issues that we propose here as starting points for thinking about digital philology activities: interaction-centres, education and re-enactment

\subsection{Heritage in interaction-centres}

The idea of a center that curates heritage in relation to the living culture of interaction is far from new. Examples are centres that develop activities to revitalise endangered cultures, such as centres that promote the Sami-culture in Finland, or centres that promote the literacy of interacting with documents and interactive multimedia systems, such as DOKK1 in Aarhus, whose goal it is to focus on the citizen as key factor, promoting lifelong learning, cooperation, diversity and skills needed to function in the living culture of interaction.

What is new, perhaps, is the awareness that the living culture of interaction has a strong heritage component, rooted both in documentation and skills that allows one to participate in that culture. However, the major problem of the living culture of interaction is that this culture is so dynamic, lively, complex and so specifically focused on advanced skills and high-level education that quite a number of people in our society tend to loose their access to that culture. Interaction-centres therefore also have a social function in making the culture of interaction accessible to everyone.

Curating heritage in interaction-centres is therefore a major task of the digital philologist. We believe that the curation activity fits well with the so-called quadruple helix model in which city, industry, academia and smart citizens are engaged to work together to co-create and drive innovation far beyond the scope of what any one organisation or person could do alone (Carayannis \& Campbell, 2012). This model fits the idea of a living culture of interaction, driven by the ecosystem that supports it. The ecosystem is connected to the local environment with which people interact on a daily basis (the city), to the work environment that creates jobs, offering a perspective for future wealth (the industry), to the universities and research centres that provide a basis for innovation (the academia), and last but not least, to the people that participate in the development of the culture of interaction, the smart citizens that are the carriers of the interaction-heritage.

An example of such an interaction-center is the Krook in Ghent. Like the DOKK1 in Aarhus, the center is rather new (since March 2017) and it still has to prove its value as a catalyst for the culture of interaction. Nevertheless, in line with the quadruple helix model, the Krook houses a public library ( $>7000$ visitors per day), a consortium of Ghent University laboratories with a focus on interactive multimedia, and a division of IMEC, a world-leading research center in nanoelectronics for application domains such as healthcare, smart cities and mobility, logistics and manufacturing, energy. Besides this strong representation of academia and public (smart citizen), there are connections with a surrounding ecosystem, such as an institute for audiovisual archiving (viaa.be), an institute for digital culture (www.digipolis.be), a concert hall and music production center (vooruit.be) and others. Centers like DOKK1 and the Krook are de facto dealing with an interactive multimedia culture, as well as with a heritage that is created by this living culture of interaction.

The adventof such interaction-centres offers opportunities for redefining digital philology. Digital philology can be conceived as an interdisciplinary science, covering different aspects of documentation and interaction, embedded in a larger scientific community, for example, with connections to digital humanities, data science, augmented and virtual reality research, and the related 

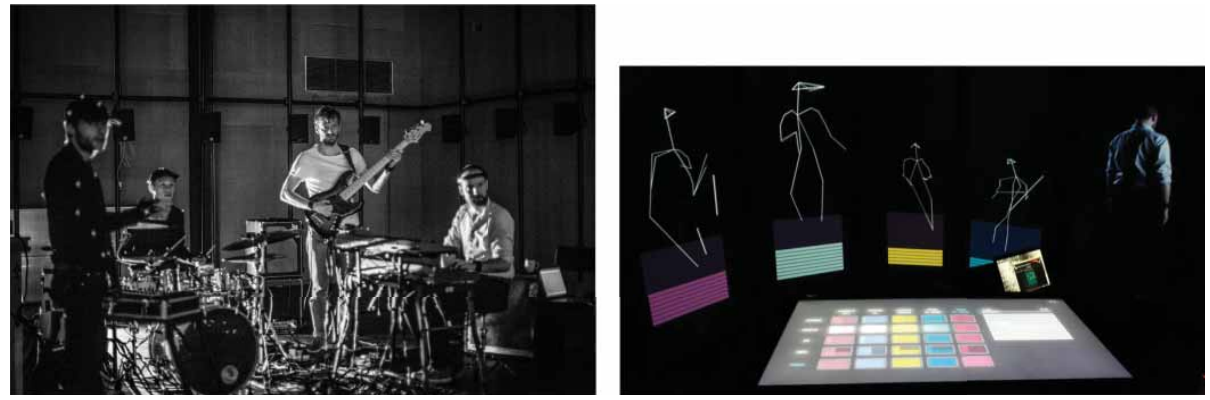

Figure 5. An interactive video clip by the band STUFF. By using motion capture technologies the performance can be recreated interactively.

engineering of the internet of things and hardware for interaction. The new interaction-centres typically offer many opportunities related to public outreach as well, for example, via immersive spaces, exhibitions and demonstrations of the interactive technologies.

A major question is how to deal with the dynamic potential offered by these centres. In fact, the main challenge is to align the particular agenda of the digital philologist's curatorship with all the ongoing activities that already promote the culture of interaction according to the above quadruple helix model.

An example of such collaboration is an interactive video clip by the Belgian band STUFF (see Figure 5). In a collaboration between STUFF and the scientists at the Krook, the performance by the band members was captured using audio, video and motion capture. It allows the audience to choose a vantage point interactively. It is a step towards a more immersive experience which recreates the live performance or a captivating derivative thereof.

Clearly, interaction-centres offer an added value to heritage, thanks to their ecosystem, which typically houses a high concentration of talented, qualified and interdisciplinary-oriented representatives of the interaction culture. In that constellation, a digital philologist is probably but a small entity and the challenge is in finding the lever that moves this ecosystem in the direction of the digital philologist's goals, that is, curating the heritage of the interactive multimedia culture, includes the interaction-heritage that the ecosystem itself produces.

In such a context, it is likely that the care of heritage can be developed as a shared care, carried by the community that pushes the culture of interaction forward. The digital philologist could make those workers aware of the inherent heritage aspects of their work, thereby pointing to the cultural value of the expressive communications developed through interactions. In such a context, creating global public awareness, setting up exhibitions, forums and sessions that show people how to document, how to restore, how to revitalise heritage properly, may become a basic ingredient of the digital philologist's practice.

\subsection{Heritage education}

It goes without saying that in our culture of interaction and rapid change, education is a crucial component. The question is what the digital philologist can contribute to the already ongoing educational initiatives, especially when seen in the context of an incubator, of collaborative work, human engineering and smart citizens.

The digital philologist can, for example, support hands-on trainings for acquiring skills in interactive multimedia technologies in relation to heritage. A concrete example would be a training of how to use the Synthi 100 in connection with a digital 3D-audio rendering system, or to develop a project in which the BilliArt system is reenacted with newer technologies than the ones used at the time. Such a training would probably be conceived within an art and science context, i.e. the idea that art and science can push each other forward in the spiral of cocreation and innovation purposes of the ecosystem that drives the culture of interaction.

Heritage education is a necessity in view of the importance of skills and habits. Given the collective responsibility for care about heritage, it will be necessary to focus more attention to people's education about how to deal with heritage issues. The sudden interest in the exhibition of the Synthi 100 seems to show that a shared collective responsibility is growing. It could be the digital philologist's task to stimulate heritage education, either in the school curriculum, and/or in the postschool long-term education of all people, whatever their age is.

Heritage education also implies outreach, which is based on facilities such as immersive spaces, co-creation spaces and on reflective activities that focus at upon issues related to the nature of digital philology, including reflections upon interaction and documentation, with an outreach to public fora. 


\subsection{Heritage engineering}

Clearly, technology will play a dominant role in the activities of a digital philologist. The current digital philologist's focus on materiality will certainly be extended with a more dynamic multi-perspectivistic focus on databases. In addition, as curator of the interaction culture, the focus on technology will also be on the expressive communication potential, using technology for setting up multimedia installations that deal with these expressive communications. Both documentation and interaction involve a solid engineering perspective that copes with the digital philologist's interest in curating heritage.

At this point, a distinction can be made between engineering methods and engineering services, see Six (2018). Engineering methods offer particular procedures to accomplish new insights that are useful components in the living culture of interaction. An engineering method abstracts, models and categorises aspects of heritage data that allow for new functionalities in an interaction culture. Often computational methods are used not unlike the ones discussed in , for example, McCarty (2005). In contrast, engineering services are more utilitarian and, in a sense, more supportive to other activities. The services' typical offer the technological basis that supports various tasks such as the implementation of databases, data mining techniques and so forth. Engineering services would typically facilitate the transfer from interactive heritage to document heritage and back, whereas engineering methods would typically inform on aspects (abstractions, features) of interaction that are relevant to documents.

The engineering profile of a digital philologist would be that of a person who engineers the heritage of interactive multimedia systems by providing tools and services that foster the exploration of expressive communication exchange. It is likely that such an engineering profile would balance between engineering and humanities and between developing services and proposing methods.

However, when focusing on interaction, the heritage value is in the experience, the kind of experience, the focus of that experience, the way in which the experience is shaped, the rituals that frame that experience and so on. There is much that can be documented here, but the ultimate value of interactive systems heritage is probably contained in the re-enactment potential of a particular type of interactive multimedia. Documentation should allow a re-enactment of that particular type of interactive multimedia. However, re-enactment requires a good part of the knowledge of a living culture as well.

Will it be possible to re-enact our current interactive multimedia culture in 400 years from here? What kind of heritage-documents would be needed then? Well-known in the field of music are re-enactments of operas of Monteverdi, or Mozart, Schubertiades, performed in socalled authentic style, with historical costumes, gestures and music instruments. Often, these re-enactments are based on heritage-documents. However, the machinery can also be combined with very advanced augmented reality and virtual reality applications. Related to this are the commercial audio-visual re-enactments for film and multimedia industry. More in line with interactive multimedia culture, perhaps, are re-enactments of modernistic and avant-garde works. Again, due to obsolete technologies, the re-enactment may require studies of how modern technology can replace old and lost analogue equipment while still offering a degree of veridicality, or authenticity.

The examples may be far-fetched but we see a picture emerging: The interactive culture is in the need of documentation that has re-enactment capacity. However, such a re-enactment may only be possible when that heritage is part of the living culture, even when the technological devices that support expression are not the original ones. Monteverdi's opera can be re-enacted, because its art forms part of a living culture of opera making. However, Hutereau's documented African music may be more difficult to re-enact in a Western context, except when carriers of the African heritage, through cultural exchange or immigration, would take the lead in it.

\section{Conclusions}

The goal of the philological research can be defined as a care for the culture of interaction, aimed at handling (multimedia) interaction in the most optimal way (with love) such that veridicality, long-term preservation, easy access and so on, is ensured. Based on a limited number of examples, we drew attention to a multi-perspectivistic view on digital philology. Its challenge is indeed concerned with frozen document-heritage as well as with living interaction-heritage. Although the goal is to find a proper balance between these two types of heritage, we argued in favour of a new definition of digital philology, one in which the love of heritage also envisions new developments in the culture of interaction.

Understanding the nature of the culture of interaction may be a key element in the re-definition of digital philology. We strongly believe that new initiatives, such as the interaction-centres and their associated ecosystem, which pop up in different countries will play a major role in the future culture of interaction. Therefore, we believe that there is a place for future digital philologists in those ecosystems with new activities related to cultural incubators, the coordination of collaborative effort 
towards heritage preservation and disclosure, the development of heritage engineering models for interaction culture and re-enactments, and last but not least, the development of educational programs directed towards new interaction-heritage.

\section{Disclosure statement}

No potential conflict of interest was reported by the authors.

\section{Funding}

This work was supported by an FWO Methusalem grant titled 'Expressive Music Interaction'.

\section{ORCID}

Marc Leman (D) http://orcid.org/0000-0002-9780-2194

Joren Six (D) http://orcid.org/0000-0001-7671-1907

\section{References}

Bressan, F., \& Canazza, S. (2014). Digital philology in audio long-term preservation: a multidisciplinary project on experimental music. Procedia Computer Science, 38, 48-51.

Bressan, F., Canazza, S., Vets, T., \& Leman, M. (2016). Hermeneutic implications of cultural encoding: A reflection on audio recordings and interactive installation art. In Italian research conference on Digital Libraries (pp. 47-58). Cham: Springer.

Briot, J.-P., Hadjeres, G., \& Pachet, F. (2017). Deep learning techniques for music generation-a survey. arXiv preprint arXiv:1709.01620.

Carayannis, E. G., \& Campbell, D. F. (2012). Mode 3 knowledge production in quadruple helix innovation systems (pp. 1-63). New York: Springer.

Darwin, C. (1890). The expression of the emotions in man and animals. London: Cambridge University Press.

Elias, N., Dunning, E., Goudsblom, J., \& Mennell, S. (2000). The civilizing process: Sociogenetic and psychogenetic investigations. Oxford: Blackwell.

Eliasoph, N., \& Lichterman, P. (2003). Culture in interaction. American Journal of Sociology, 108(4), 735-794.

Goffman, E. (1967/2005). Interaction ritual: Essays in face to face behavior. New Brunswick, NJ: AldineTransaction.
Hume, D. (1777). An enquiry concerning human understanding. Oxford: Clarendon Press.

Hutereau, A. (1927). Histoire des peuplades de l'Uele et de l'Ubangi. Bruxelles: Goemaere.

Jockers, M. L. (2013). Macroanalysis: Digital methods and literary history. Champaign, IL: University of Illinois Press.

Leman, M. (2016). The expressive moment: How interaction (with music) shapes human empowerment. Cambridge: MIT Press.

Lorenz, R. C., Gleich, T., Gallinat, J., \& Kühn, S. (2015). Video game training and the reward system. Frontiers in Human Neuroscience, 9, 40.

Maes, P.-J., Lorenzoni, V., Moens, B., Six, J., Bressan, F., Schepers, I. \& Leman, M. (2018). Embodied, participatory sensemaking in digitally-augmented music practices: Theoretical principles and the artistic case "SoundBikes". Critical Arts. doi:10.1080/02560046.2018.1447594.

Manovich, L. (2001). The language of new media. Cambridge: MIT Press.

McCarty, W. (2005). Humanities computing. London: Palgrave Macmillan.

Mertens, W. (1983). American Minimal Music - la Monte Young, Terry Riley, Steve Reich, Philip Glass. London: Kahn \& Averill.

Salimpoor, V., Zald, D., Zatorre, R., Dagher, A., \& McIntosh, A. (2015). Predictions and the brain: How musical sounds become rewarding. Trends in Cognitive Sciences, 19(2), 86-91.

Seiderer, A., \& Schellow, A. (2017). Writing within colonial films. Critical Arts, 31, 87-101.

Six, J. (2018). Engineering systematic musicology - methods and services for computational and empirical music research $(\mathrm{PhD}$ thesis). Retrieved from https://biblio.ugent.be/publication/ 8544101

Six, J., Bressan, F., \& Leman, M. (In Press 2018). Applications of duplicate detection in music archives: From metadata comparison to storage optimisation - The case of the Belgian Royal Museum for Central Africa. In Proceedings of the 13th Italian Research Conference on Digital Libraries (IRCDL 2018).

Tomasello, M. (2010). Origins of human communication. Cambridge, MA: The MIT Press.

Turner, J. (2014). Philology: The forgotten origins of the modern humanities. Princeton: Princeton University Press.

Vets, T., Nijs, L., Lesaffre, M., Moens, B., Bressan, F., Colpaert, P., Lambert, P., Van de Walle, R., \& Leman, M. (2017). Gamified music improvisation with billiart: a multimodal installation with balls. Journal on Multi-modal User Interfaces, 11(1), 25-38. 